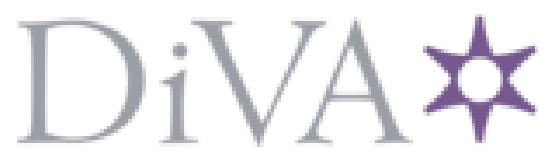

http://www.diva-portal.org

This is the published version of a paper published in Technological forecasting \& social change.

Citation for the original published paper (version of record):

Jansson, F., Lindenfors, P., Sandberg, M. (2013)

Democratic revolutions as institutional innovation diffusion: Rapid adoption and survival of democracy.

Technological forecasting \& social change, 80(8): 1546-1556

http://dx.doi.org/10.1016/j.techfore.2013.02.002

Access to the published version may require subscription.

N.B. When citing this work, cite the original published paper.

Permanent link to this version:

http://urn.kb.se/resolve?urn=urn:nbn:se:hh:diva-2 1677 


\title{
Democratic revolutions as institutional innovation diffusion: Rapid adoption and survival of democracy
}

\author{
Fredrik Jansson a,b,1, Patrik Lindenfors ${ }^{\text {a,c, }}{ }^{\text {, }}$, Mikael Sandberg a,d,* \\ a Centre for the Study of Cultural Evolution, Stockholm University, SE-106 91 Stockholm, Sweden \\ b Institute for Futures Studies, Box 591, SE 10131 Stockholm, Sweden \\ c Department of Zoology, Stockholm University, SE-106 91 Stockholm, Sweden \\ d School of Social and Health Sciences, Halmstad University, Box 823, SE-301 18 Halmstad, Sweden
}

\section{A R T I C L E I N F O}

\section{Article history:}

Received 24 February 2012

Received in revised form 1 February 2013

Accepted 3 February 2013

Available online $\mathrm{xxxx}$

\section{Keywords:}

Democracy

Autocracy

Transitions

Consolidation

Institutions

Revolutions

\begin{abstract}
A B S T R A C T
Recent 'democratic revolutions' in Islamic countries call for a re-consideration of transitions to and from democracy. Transitions to democracy have often been considered the outcome of socio-economic modernization and therefore slow and incremental processes. But as a recent study has made clear, in the last century, transitions to democracy have mainly occurred through rapid leaps rather than slow and incremental steps. Here, we therefore apply an innovation and systems perspective and consider transitions to democracy as processes of institutional, and therefore systemic, innovation adoption. We show that transitions to democracy starting before 1900 lasted for an average of 50 years and a median of 56 years, while transitions originating later took an average of 4.6 years and a median of 1.7 years. However, our results indicate that the survival time of democratic regimes is longer in cases where the transition periods have also been longer, suggesting that patience paid in previous democratizations. We identify a critical 'consolidation-preparing' transition period of 12 years. Our results also show that in cases where the transitions have not been made directly from autocracy to democracy, there are no main institutional paths towards democracy. Instead, democracy seems reachable from a variety of directions. This is in line with the analogy of diffusion of innovations at the nation systems level, for which assumptions are that potential adopter systems may vary in susceptibility over time. The adoption of the institutions of democracy therefore corresponds to the adoption of a new political communications standard for a nation, in this case the innovation of involving in principle all adult citizens on an equal basis.
\end{abstract}

(c) 2013 Elsevier Inc. All rights reserved.

\section{Introduction}

Recent uprisings in North Africa and several Islamic countries are often being called 'democratic revolutions' and

\footnotetext{
* Corresponding author at: Centre for the Study of Cultural Evolution, Stockholm University, SE-106 91 Stockholm, Sweden. Tel.: + 46704936 619.

E-mail addresses: fredrik.jansson@intercult.su.se (F. Jansson), Patrik.Lindenfors@zoologi.su.se (P. Lindenfors), mikael.sandberg@hh.se (M. Sandberg).

${ }^{1}$ Tel.: + 468163955

${ }^{2}$ Tel.: + 46703418687 (mobile).
}

even the beginning of 'a new wave of democratizations'. This terminology, however, reflects hopes rather than likely outcomes. The revolutionary transition processes have been initiated in autocratic countries with poor conditions for consolidated democracy in the short perspective. We will more likely instead see a series of weakly designed post-autocracies, failing to fulfill too far-reaching aspirations of the grass-root opposition and therefore later reversals into new forms of non-democracies.

On the other hand, this pessimistic view may be wrong. Communication technologies and social networks might spark not only uprisings but also more informed discussions, debates, formations of organizations and negotiations on

0040-1625/\$ - see front matter @ 2013 Elsevier Inc. All rights reserved. http://dx.doi.org/10.1016/j.techfore.2013.02.002 
how to institutionally create and sustain a democracy. But such discussions, debates, formations of organizations and negotiations, along with political processes for preparation and implementation of new constitutional designs, require substantial time. An issue is also whether such processes can compensate for lack of the traditional requisites of democratization, such as an already existing rule of law, freedom of a civil society, an institutionalized political system and economic society, as well as an efficient public administration [1]. Political scientists are now busy in trying to understand the mechanisms of transitions to democracy in our time, and how they may differ from those of earlier waves of democratization (see for instance recent issues of Journal of Democracy).

In this article, we propose to use the analogy of innovation diffusion in evolving systems to understand the transitions to democracy as adoption of democratically essential institutions in the population of nation-states in the world. We find several grounds for this proposition. Recent research on institutional dynamics reveals its systemic, evolutionary and innovative character [2-10]. Institutions are constraints on societies and behavior normally formed or reached as a consequence or outcome of power struggles between interest groups before their emergence $[5,8,11]$. In this sense they can be understood as social contracts or equilibria in national socio-economic systems $[3,4,11,12]$. Their evolutionary character is the consequence of natural (unintended, historical) selection processes, and, in learning processes on a global and historical scale, increasingly also artificial (intended, political) ones $[4,13]$. Thereby, some fundamental institutions or societal contracts are wiped out as unviable in the historic and geographic context they happen to emerge (say, the Weimar republic), some oscillate in dynamic equilibria between autocracy and democracy (say, Argentina), some prove extreme survivability in their original democratic form (say, most first wave democracies, such as Sweden, see [14]). In the longer run, democratizers have managed to learn from previous mistakes and democratic failures, so that now, in general terms, some guiding principles may frame power struggles and negotiations between major interest groups in non-democratic nations subject to "democratic revolutions". However, as a consequence of the diffusion and saturation process on a global scale in the last centuries, the countries still non-democratic can be argued to also have the most idiosyncratic, diverse and unfavorable conditions for emergence and survival of democratic institutions. One should therefore not forget to consider the point of institutional departures as well as institutional pathways to democracy in the analysis of democratic survivability.

As all evolutionary processes, institutional evolution should not be considered predictable or deterministic [15]. However, given the trial-and-error institutional learning processes on a global scale, and standard models of diffusion of innovations, projections of likely further democracy diffusion can in principle be made (such as Fischer-Pry transforms, Bass models and SIR epidemiological models, see [16-21]). If these models are in principle adequate, then the institutional origins and pathways are already accounted for in the model as time varying fractions of susceptible units and therefore not influencing the standard diffusion pattern. It is therefore an empirical question whether the institutional departure and pathways influence adoption of democracy or if the innovation diffusion models are correct.

We argue that such an approach, consistent with the analysis of innovation diffusion in evolving systems-such as diffusion of communication standards among regions or countries-analogically applies to the evolution and diffusion of democracy on a world scale [18]. The susceptible "host" in this case is the nation-state that may or may not adopt a democratic standard for political communication [10,14]. The unit of selection is the package of institutions that are essential for democratic political communication. Our proposed approach therefore motivates a study of transition periods, in which contracts on new political communication standards are made, marking institutional pathways intended to sustaining democracy in the longer run. In this article, we therefore primarily consider (1) time and (2) institutional paths in their relation to democratic revolutions, transitions and survival. Our central questions are formulated in a way that may help us in assessing the validity of innovation diffusion models: Is duration of transitions positively related to the survivability of democracy in the longer run? Are specific institutional paths more common or more conducive as routes to democracy?

\section{Definitions}

Some definitions are warranted. 'Transition' is normally understood as a passage from one state to another in a general sense, and 'revolution' is thus a specification: “a major, sudden and hence typically violent alteration in government and in related associations and structures" [22]. This implies that a transition can either be revolutionary or incremental in its changes of institutional and organizational setup of the nation in question. Transition as a concept in political science corresponds to the process of adoption in innovation science. Drawing on Schumpeter, we define 'innovation' as "doing of new things or the doing of things that are already being done in a new way (innovation)" [23: 151], that is, "new combinations" [24: 66], however in this case related to politics and institutions, rather than economics and management principles. Since his Capitalism, Socialism and Democracy [25], 'democracy' has generally been understood as an "institutional arrangement for arriving at political decisions in which individuals acquire the power to decide by means of a competitive struggle for the people's vote". Inspired by Schumpeter, Dahl has pointed out [26], and following him, Vanhanen [27], that democracy can be generalized as an on-going interplay between increased political participation and elite contestation. A variety of conditions have been suggested as correlates or determinants of successful transitions and stable democracy. Since the 1950s, data and statistics have been increasingly helpful in the systematic investigation of which conditions are necessary or favorable for democratic survival (see the operational definitions in the section below). In this context, several definitions of 'consolidation' of democracy have been advanced, to which we will return in the analysis below.

\section{Materials and methods}

Democratization on a world scale has typically been quantitatively analyzed in terms of the cumulative change 
into one minimum value of democracy, often on the basis of the polity data sets, in which institutional scores are available for all countries with populations of more than half a million (currently 164) and covering all years from 1800 [19,28-32]. The value of this data set for studies of democracy has been questioned on the grounds that the ordinal scale character of data is seldom considered [33]; but here we exploit the categorical character for our analysis of transition paths to democracy. ${ }^{3}$ In this dataset, for each stage in time since 1800 , all countries have been coded with set values of six component variables. This scheme (see Appendix A) makes it possible to classify any specific political regime at any point in time into one of 4550 possible institutional arrangements, which in turn translates it into a polity score on a 21-point scale from autocracy to institutional democracy. History has traced out some of these. As exceptions, the Polity IV data set classifies countries as being in 'interruption', 'interregnum' or 'transition periods', neither of which translates into any polity score.

In the Polity IV data series, scores on national political regime characteristics over the years 1800-2008 are weighted by means of a specified algorithm to produce autocracy and democracy scores. The sum of these two scores in turn makes up the polity score, which functions as a measure of location on an autocracy-anocracy-democracy continuum for each nation ('anocracy' defined as having some but not all of either autocratic or democratic institutions) [30]. Anocracy is typical for a policy in transition from or to democracy, but may theoretically also be a state of stasis. As recommended in the Polity IV user's manual, we here define an autocracy as a country with a polity score of -6 or lower, while democracies are countries with a polity score of 6 or above. ${ }^{4}$ Regimes scoring between these values, that is, between and including -5 and 5 , are those referred to as anocracies. ${ }^{5}$

Data are presented in Appendix B in a table that includes all transitions between autocracy and democracy (i.e. all transitions that started in one of these states and ended in the other) that have taken place in the world system of nations from 1800 to 2008. In Appendix B table, transitions are given from the last day with an autocratic or democratic government to the first day with a democratic or autocratic government and the number of days in between defines the length of the transition period. Renamed countries are included in the analysis and represented by their present name in the table. Countries dissolving during a potential transition period (for example, USSR was an autocracy until 1989, and dissolved, while being an anocracy, into several independent republics, some of which are democratic, and some still autocratic), or becoming part of other countries (such as democratic West Germany and autocratic East

\footnotetext{
3 The polity data set and many of its users have also been criticized for not treating democracy as a latent variable and transforming the error-prone democracy index into a more reliable set of democracy indicators by means of an ordinal item-response model [34]. This important critique and methodological proposition have fewer implications for this study, since we are not using democracy as an independent variable in our investigation.

4 The criteria for the classification of democracy are not arbitrary, but defined in the Polity documentation. We do not see the utility of utilizing other cut-off points for our analyses since most studies accept Polity recommendations.

5 See Appendix A for operational definitions used in this study.
}

Germany uniting into democratic Germany), are listed as separate countries and the transitions in question are not included in the analysis.

We thus identified every case in which a nation, first, had changed institutionally at all, and, second, undergone transition from being an autocracy to being a democracy, possibly passing several anocratic institutional arrangements, and vice versa. In analyzing these transitions or adoption processes, we utilized the exact dates provided in the Polity data set throughout our analyses (rather than using the less exact year-by-year data). Focusing on the transitions, the number of days each transition had taken was recorded.

Our next concern was the relationship between the transition speed and success of the resulting democracy, that is, the relation between transition time (adoption speed) and survival (innovation life time). A log-log regression was made of transition time on duration of survival, an analysis by definition excluding the current and therefore yet not failed democracies.

To further investigate the relationship between rapidity of the transition and the stability of the resulting democracy and be able to include democracies existing today, we conducted a series of tests with different cut-off points in the number of days a regime had to remain a democracy in order to count as a success. Regimes that remained democracies during the allotted amount of time were counted as successes, while those that reverted to autocracy during this time were counted as failures. Democratic regimes that had been democracies for less time than the allotted cut-off number of years and not failed had in this case to be removed from the analysis, since it is still unknown whether these will be successes or failures, while all countries reaching the cut-off time could be included, also those existing today. We then compared the 'successful' democracies with the 'failed' ones with regard to the number of days it had taken them to reform from being autocratic to being democratic. Lastly, we plotted each cut-off point against the number of days from autocracy to democracy (adoption time) in order to identify a possible consolidation-preparing period (optimal for survivability).

We also studied the reform paths of nations to democracy from autocracy and vice versa. All anocratic states between autocracy and democracy were noted, as was the number of nations reforming according to each recorded path. This was done in order to investigate if any specific pathway of democratic reform was more likely to be successful than other pathways.

\section{Theory}

In the early 1970s, Gurr, analyzing his Polity data, reported that continents differ greatly in terms of democracy's persistence [30]. Not surprisingly, the fall of the Berlin wall in 1989, elections in Poland the same year, and subsequent years in other previously Soviet dominated nations and republics, lead first to intensive research on modes and paths of transition to democracy, and later to an increasing interest in the analysis of conditions for consolidation in newly established, "third wave" democracies [35-40]. After the third wave, with Huntington, we consider negotiated transformations, replacements, and 'transplacements', produced by the combined actions of government and opposition, supportive of consolidation [41]. In order for democracy to become "the only game in town" [1], 
as mentioned in the introduction, there need be specific institutions in place, assuming a functioning state apparatus: those of a civil, political and economic society, as well as rule of law and a capable bureaucracy. All these proximate factors are subject to influence from more ultimate socio-economic development processes within nations, as well as catalyzing conditions globally, such as communications $[18,42]$.

It is not surprising that democratization on a world scale for these reasons has been found to follow time and space diffusion patterns $[18,19,29,36,43-49]$. As a consequence, one would also expect later adopters to undergo shorter transitions than earlier -though previous studies of that have not been found. Seen from the historical, or time-series data perspective, path dependencies [50] are also likely. As suggested already by Moore, ownership structures in a nation's agricultural sector lead to different types of class and coalition developments, which in turn, decades or even centuries later, provide conditions for quite diverse political systems [51]. In a similar vein, Burton et al. have suggested a path dependent account of different types of consolidations in Latin America and Southern Europe, in which elite settlement is considered essential for a later consolidation of democracy [52]. Though there are deductive-descriptive analyses of a prior regime types to democracies, such as those of Huntington [36] and Linz and Stepan [35], who have inspired many others [for a review, see 53], we have not found examples of quantitative mapping of all prior institutional combinations.

In an early empirical study of democratic consolidation published in 1998, Gasiorowski and Power suggest two definitions of consolidation but as a consequence of data analysis arrives at a third [54]. Building on the ideal-type proposition in previous studies of consolidation, they first defined consolidation as (1) whether a new democratic regime survives the holding of a second election for the national executive, subsequent to the founding election that inaugurated the regime, or (2) that a consolidation occurs when a democratic regime survives an alternation in executive power through constitutional means, that is, an unambiguous change in the partisan character of the executive branch. However, as they studied the likelihood of survival of democracy on the basis of data on 66 identified transitions among 97 Third World countries that had populations of at least 1 million in 1980, they inductively arrived at a preferred third way of defining consolidation, namely (3) a 12-year survival period after transition to democracy, motivated by the fact that there is a decrease in the likelihood of democratic breakdown after that period. They argue that the percentages of new democracies that remained democratic in each of the first 30 years after their transitions fell sharply during the first 12 post-transition years (when 37\% remained democratic), but that after that period, the percentages fell more slowly, and after 30 years, 22\% were still democracies. New democracies, they argued, are more fragile, but much less so after a dozen years.

These results have been contested. Defining the concept of a 'honeymoon' effect as increased survivability in new democracies, and making empirical tests on regime data 1951-1995, Bernhard et al. [55] came to the conclusion that statistical evidence indeed indicates a honeymoon for one or two years after transition, but not longer. Interestingly, they also find an 'antihoneymoon effect' in the sample during the first two election periods in cases where the new democracy had faced economic contraction.
Adding to these results, in relation to consolidation versus survival, Svolik has argued that we need to distinguish between survival due to consolidation and survival due to other factors: "consolidation amounts to being 'immune' to the causes of democratic breakdowns", while "democracies that are not consolidated-transitional democracies-may also survive because of some favorable circumstances" [56]. His results indicate that the probability of consolidation increases with the age of a democracy, though he does not specify any particular consolidation periods in terms of age of new democracies.

In relation to these studies, we have hypothesized that the longer the transitions from various non-democratic states to democracy, the more likely it is that democracy will survive in the longer run. Instead of only looking at the relationship between the age (or passage of a certain period of time) of a new democracy from the time of adoption versus survival or persistence in the longer run, we focus on the duration time of the transition period in relation to survival time of the democratic regime. We have not found previous quantitative analyses of this relationship. The argument for such an analysis would be that transitions to democracy involve so many bargaining processes between major interests, so much institutional innovations, and so extensive political deliberations in the parliament, government, governmental committees and agencies, and so forth, that the process to implement them all on the national as well as regional and local level must take at least a certain minimum of time for making later democratic success possible in all these steps. Transitions that proceed exceedingly long, however, may more likely suffer from stalemates and other severe obstacles so that the consolidation and survival of any resulting democracy is also threatened $[35,38,40,41,52,57,58]$. Consequently, one may also suggest that successful transitions to democracy take similar institutional paths, and that there are a few fundamental institutions that need be implemented simultaneously in order to create the complex of institutions called democracy. As we focus here on transition time, institutional paths and survival of democratic regimes, we postpone a comprehensive analysis of survival times to other likely covariates, such as socio-economic (structural) factors, political culture traits, economic variables, communication, geopolitical vicinity, and so forth.

Given an innovation perspective on the institutional transition to democracy, such as in the application of diffusion models, we would not expect various origins or institutional idiosyncrasies among potential adopters to be critical, since a variety of fractions or even a dynamic fraction susceptible to the innovation may already be assumed in these models $[17,20,59]$. Therefore, accepting diffusion model perspectives, points of departure of the autocratic regime, and the institutional pathway towards democracy, should not matter. Analyses of existing data can help us assess the validity of that hypothesis.

\section{Results}

\subsection{Transitions/adoption processes}

Data show that most transitions occurred in the 20th century. There was one transition to autocracy in the 19th, 40 in the 20th, and 2 in the 21 st century. In the other direction, 
transitions to democracy, 10 out of 79 transitions originated in the 19th, 67 in the 20th and two in the 21st century. Transitions were more rapid in the 20th century: transitions to democracy starting before 1900 lasted for an average of 50 years and a median of 56 years, while transitions originating after that year took an average of 4.6 years and a median of 1.7 years. Only one transition in the 19th century was more rapid than any of the following ones (France on December 6, 1869, initiated a relatively fast transition to democracy, which still took more than eight years). Even though transitions were more rapid after 1900, their speed has not increased since.

The average duration of a period without changes to any of the six institutional variables is 9.3 years, with a median time between changes of 4.6 years. The most stable institutional arrangements are full autocracy (311141, see Fig. 4 and definitions of institutional arrangements in Appendix A) and full democracy (334755), lasting an average of 31 and 21 years without changes, respectively. ${ }^{6}$ The most unstable arrangement is the one referred to as a transition period ( -88 ), averaging 2.0 years. In the 860 cases that institutional transitions have occurred, there was a majority with a direction towards increased democracy (511 cases) rather than in the opposite direction (349 cases; binomial test: $\mathrm{p}<0.001$ ). Over time, such institutional changes in favor of democracy have resulted in an increasing number of democracies across the globe $[19,29,43,44,47,49,60]$. Previous analyses of direction and length in institutional leaps also show that transitions tend to cluster in only two major regime-types: autocracy and democracy [14]. Change is much more common within these systems than between them. The overall picture is thus one in which two major locations of institutional change dominate, while transitions between them, whether incrementally or in long leaps, are relatively scarce.

We now instead focus on the relatively scarce transitions to democracy as defined previously (Fig. 1a and b). The figures reveal that these transitions, however peaceful they may be, seem revolutionary in the sense that they occur as rapid leaps (revolutions), not gradual reforms. The median time required for moving a country from autocracy to democracy is 2.4 years, with $75 \%$ of these transitions occurring within 11 years (Fig. 1a). Similarly, the median number of intermediate regime states between autocracy and democracy is one state, with 78\% of the changes occurring via at most two states (Fig. 1b). Revolutions in the sense long and quick institutional leaps towards democracy are much more common than incremental and slow transitions.

Concerning transitions to autocracy, the institutional length and speed of steps are even more pronounced. More than half of the transitions from democracy to autocracy were immediate leaps, with $75 \%$ of the changes occurring within 1.4 years (Fig. 1a). A total of $93 \%$ of these changes occur via at most one institutional state (Fig. 1b). Although democratization is a rapid process, the reversion to autocracy is even faster.

Our analysis of data on speed, direction and institutional length of transitions to and from democracy thus suggests

\footnotetext{
${ }^{6}$ If we include the regimes still running, the average remains mainly
} unchanged, except for full democracy, which increases to 38 years. that the last centuries show a pattern of revolutions rather than incremental steps towards democracy (as well as to autocracy), and more so in the 20th century than in the 19th. Against the background of the extensive literature on factors related to democratization $[18,27,29,31,41,42,47,49,61,62]$, one might conclude that democratic transitions follow more dramatic sequences of events than is the case with most of what has been put forward as candidates of explanatory conditions and determinants. The sparking of events, however, may be caused by other factors than those required for a successful transition.

\subsection{The survival of democracy}

Some democracies fail to survive. As mentioned earlier, in particular under economic stress, the viability of the new democratic institutions is at stake.

Considering these factors, we have hypothesized that countries that followed a slower institutional transition path from autocracy to democracy would be more stable and hence less likely to revert into autocracy. Carefully and well-negotiated institutional steps towards democracy should lead to survivability of the resulting democracy. Our analysis indicates that the hypothesis seems correct and reveals that survival time of democratic regimes is related to the length of the transition periods from autocracy to democracy. Since transition times were much longer in the 19th century, the relation between transition and survival time may be an effect of a generally slower rate of institutional change in the past. However, from 1900 onwards, the lengths of transitions drop and there is no significant correlation between year and days in transition.

With transitions before 1900 excluded, Fig. 2 suggests that the variance of the (log-transformed) duration of transitions explains around one fifth of the variance in the (log-transformed) number of days as democracy ('survival') -yielding an $R^{2}=0.183$-and indicating the importance of a prolonged transition and therefore a longer preparation time for increasing the survivability of democracy. ${ }^{7}$ The relationship becomes even more pronounced when also including the data from the 19 th century $\left(R^{2}=0.243\right) .{ }^{8}$ Note, however, that these results hinge on the inclusion of Haiti and Venezuela in the analyses. Removing these, the analysis becomes non-significant. The subset of failed democracies is simply too small to draw firm conclusions utilizing this manner of analysis.

The results reported above are biased in the sense that they are only based on failed democracies. To further investigate

\footnotetext{
7 A regression of the data from 20th century yields: $y=0.133 x+2.976$, $\mathrm{p}=0.067 ; R^{2}=0.184 ; F_{(1,17)}=3.822$. The analysis was carried out on logtransformed data because the data was not normally distributed. Due to the significantly longer transitions in the 19th century, only transitions originating thereafter are included. One anonymous reviewer suggested survival analysis rather than log-log regression. We are grateful for this suggestion and have planned to switch to using survival analyses in future analyses of the data. However, we here were attempting to find a border condition where the influence of the independent variable (transition time) switched from being an important explanation of survival times to where it was no longer important. We have not found any such algorithm in survival analyses.

8 A regression on data from both the 19th and the 20th century yields: $y=0.159 x+2.959, p=0.014 ; R^{2}=0.243 ; F_{(1,22)}=7.065$. A corresponding figure is given in supplementary materials to this article.
} 
a

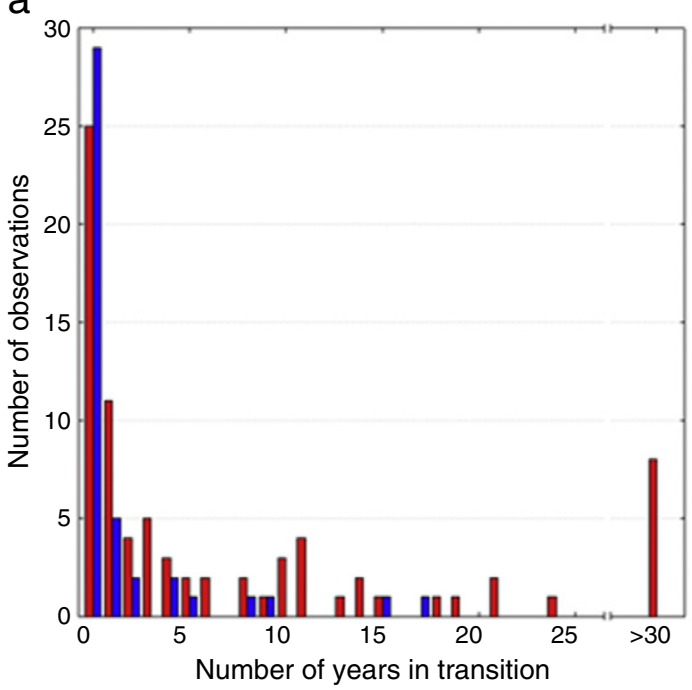

b

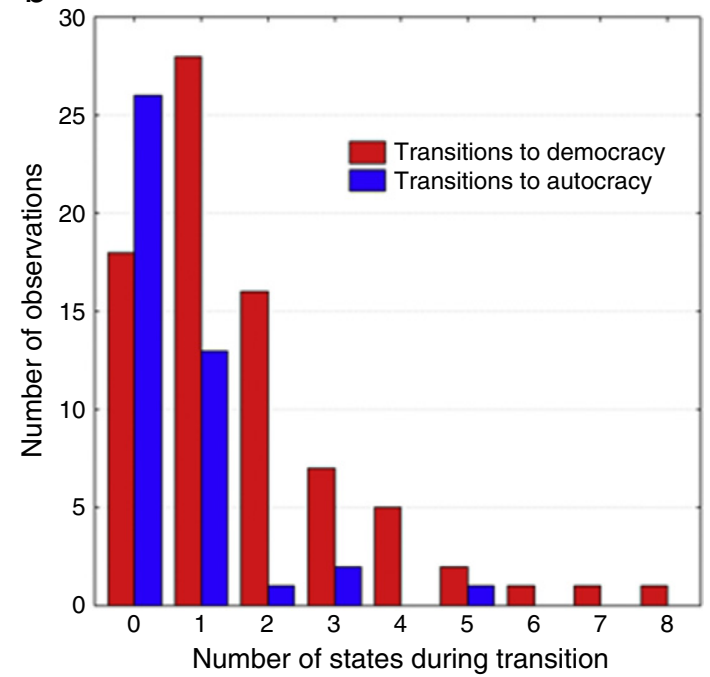

Fig. 1. a and b. Number of years and institutional states in transition to democracy vs. autocracy. Changes between autocracy and democracy, and vice versa, tend to occur very quickly, both if (a) measured in units of time and if (b) measured in units of intermediate institutional arrangements.

Source: Lindenfors et al. (2011).

the influence of the length of the transition period, we constructed a test that could also include democracies that have (yet) not failed. This test also enabled us to identify a potential 'consolidation-preparing' period of transition for democracy-an average number of years after which the length of the transition period becomes unimportant for the survival probability of the democratic regime. We compared transition periods between successful and unsuccessful democracies. If duration of reform is an important variable in predicting the likelihood that a regime remains a democracy, then one should expect a significant difference between 'successes' and 'failures' in the number of days taken to reform the country from autocracy to democracy. The task of determining how many years a democracy has to be stable in order to count as a success is an arbitrary one. To overcome this problem, we conducted statistical analyses testing for this difference using all different cut-off points possible as to when a regime should count as a 'success' (see Fig. 3 ). ${ }^{9}$

We removed comparisons involving less than ten countries in either category. We found a significant difference between successful and failed democracies for cut-off points lower than 12.12 years using Mann-Whitney U tests, but non-significant for cut-off points higher than that, even though a difference persisted of about one to two standard deviations in the number of days between successes and failures. Since transitions took longer during the 19th century than later, and since this could potentially have unduly influenced our results, the analyses were carried out with the 19th century excluded. The results with the 19th century included were qualitatively similar, however, again indicating a consolidation-preparing

\footnotetext{
${ }^{9}$ We have accounted for sample size by removing comparisons involving less than ten countries in either category. This criterion comes to play only at the edges of the graph (Fig. 3), so there is no real concern around the central portion of the graph, which is where we draw our conclusions about the 12year time period. Further, we do not see any possible way of building a model where we can calculate an interaction term with a time spline except through iterative tests stepping through different possible cut-off points.
}

period of twelve (12.41) years. This provides support for the actual existence of a consolidation-preparing period, as well as a quantification of it. After a rapid transition to democracy, the probability of survival is lower than after a slow transition, but this effect is not statistically significant after twelve years.

\subsection{Institutional paths}

Transitions may follow different institutional paths. As mentioned, Huntington describes several processes, such as transformations, 'transplacements', replacements and interventions that might have several outcomes democratically [41]. Polity IV uses Eckstein's proposed dimensions of institutions [63]. Since there are as many as 4550 institutional combinations, the majority of them are not present in Polity IV data. ${ }^{10}$ Here, we explore this data set to see whether there are major or typical reform paths that countries follow during these transition periods, or if all countries follow their own unique paths. We first consider the total of 79 transitions made from autocracy to democracy. Of these, $23 \%$ have taken place through an immediate reform of an autocratic government. There have occurred 43 transitions from democracy to autocracy. Of these, $60 \%$ have taken place through an immediate reform of a democratic government (Fig. 4).

Fig. 4 gives us a Polity IV based map of all institutional paths taken between autocracy and democracy by a vector of six digits giving the values of the following six component variables: three variables on executive recruitment: (1) regulation of chief executive recruitment, (2) competitiveness of executive recruitment, (3) openness of executive recruitment; one variable on independence of executive authority: (4) executive constraints (decision rules); and finally two variables on political competition and opposition: (5) regulation of participation, and (6) competitiveness of participation, in that order. The digits

\footnotetext{
10 See Appendix A.
} 


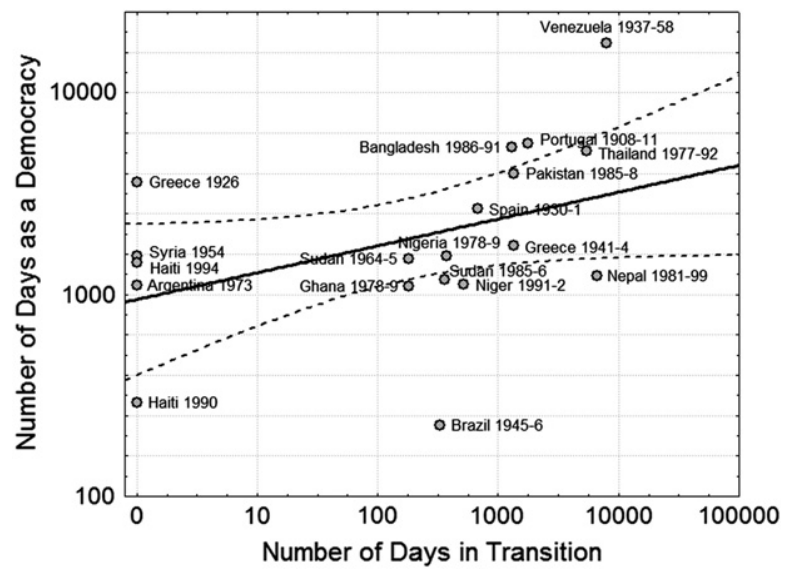

Fig. 2. Duration of transition and survival of democracy. A log-log regression plot of the transition time to reach democracy on the duration of democratic regimes. Country names are followed by years of transition.

for one institutional location (a node) should be interpreted as nominal values, and their representations are presented in Appendix A and more thoroughly in the Polity IV user's manual [32]. The width of the vertices represents how many times a transition has occurred between two institutional states, varying from 1 to 26 times, and the darker the node, the more years were spent on average in the present state. Changes between autocracy and democracy tend to happen through instantaneous leaps, as noted above. In the cases where this is not true, transition paths followed are unique for all countries (except in the cases where the steps are taken via a 'transitional period' with undefined institutional arrangements).

As the previous results indicate, most transitions between democratic and autocratic types of political regimes occur through one unique reform of the political system, or through one intermediate state. Most of these changes via an intermediate step tend to progress via the form of regime type defined in the Polity IV user's manual as a 'transition period'. Such periods are described as "quite fluid, or volatile" and "often result in unintended institutional arrangements". Because of this definition, the 'transition period' is common en route from

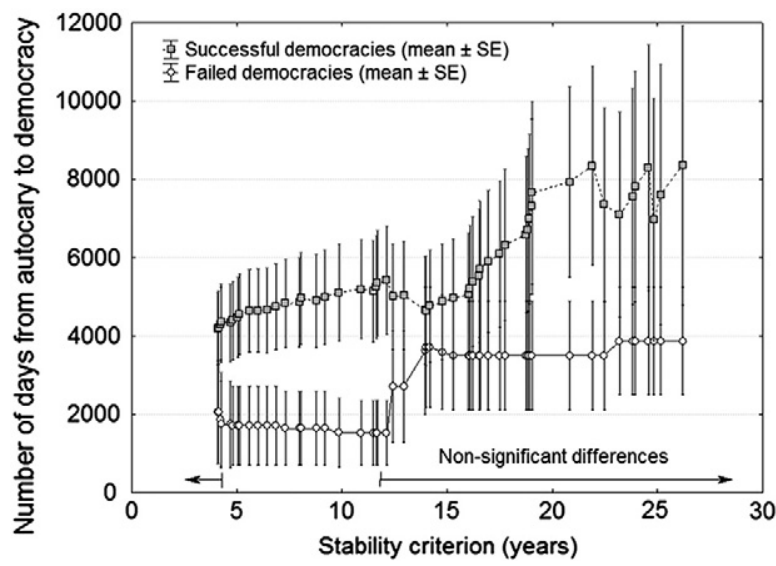

Fig. 3. The stability criterion and the transition to democracy. Mann-Whitney U tests comparing transition time between successful and unsuccessful democracies, where success is defined as duration past a stability criterion. All points where the composition of the groups changes are tested as stability criteria. autocracy to democracy, and is an intermediate state in 53\% of the transitions on the way to democracy and $26 \%$ of the transitions on the way to autocracy. This period is likely to be very different, with rapid changes, for any two countries, so even though several countries pass through this state, they are all likely to have evolved differently. In cases where other transition paths were followed, these were unique (Fig. 4). Thus, there are no well-trodden reform paths to democracy except the rapid leap; what we see is a great variety of institutional transitions to democracy. This result suggests that the actual institutional path taken during transition-at least as it is defined in terms of individual Polity IV institutional variables- can neither help us explain survival time of the resulting democracy, nor predict or imitate successful transitions.

\section{Discussion}

This article proposes a systemic innovation perspective on transitions to democracy on a world scale. Institutional set-ups of democracies are outcomes of power struggles among interest groups existing before transition and are often called social contracts or political system equilibria. They are evolutionary in the sense that they are subject to historical and political selection processes, in turn implying a historical trial-and-error learning process about which institutions work and how. (One outcome of this learning process is the emergence and evolution of political science.) Innovations in political regime institutions are thus analogous to innovation in national communication standards-they occur at a national level as a result of negotiations or power struggles between interests. We in fact suggest democracy to be considered a political communication standard of a national system in principle involving all adult citizens on an equal basis. In this study, however, for pragmatic reasons, we use Polity IV data set operationalizations of democracy and its institutions, since it covers political institutions for all nations, all years, since 1800 .

Previous political research on transition to and from democracy has generally not focused on duration and institutional step dynamics of transitions to democracy. In this study, we showed that transitions to democracy (seen as adoption processes of its packages of institutions) starting before 1900 


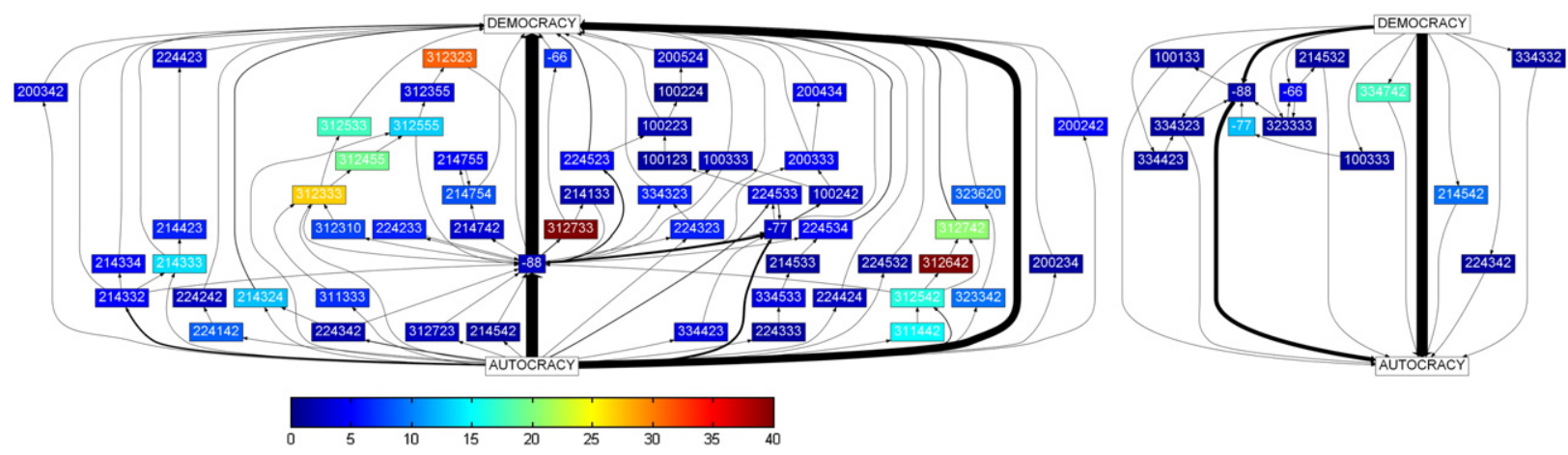

Fig. 4. Institutional transition paths to and from democracy. The digits for one institutional location (a node) should be interpreted as nominal values, and their representations are presented in Appendix A and more thoroughly in the Polity IV user's manual. The width of the vertices represents how many times a transition has occurred between two institutional states, varying from 1 to 26 times, and node color scales the years spent on average in the present state. See Appendix A for variable values indicted in the path diagram.

took much longer (with an average of 50 years and a median of 56 years) than those originating in the 20th century (with an average of 4.6 years and a median of 1.7 years). This indicates that the actual evolution of democracy took place during the 19th century, and that now reformers know what system to implement or what constraints there are to the negotiations of democracy forming institutions on a national scale.

Further, we hypothesized that the longer the transitions, the more likely the survival of the resulting democracy, with the exception for longer transitions presumably being the result of stalemates between interest or other obstacles to democracy. We also initially hypothesized that the institutional steps towards successful democracy are taken simultaneously in each transition case and in a similar fashion in all transitions. However, we also made the qualification that if the application of innovation diffusion models is considered adequate for our understanding of democratization on a world scale, then national differences may already be accounted for in these models as varying fractions susceptible to democratic innovation. If diffusion models are valid, then variety in susceptibility to the democratic idea of institutional setups may be an assumption and institutional pathways to democracy may differ accordingly.

Results of this study indeed indicate that only scarcely have there been slow incremental transitions to democracy, but when this has been the case, democratic survival in the longer run is more likely. Our approach to determining the consolidation-preparing period suggests the upper limit to approximately 12 years before transitions become insignificantly conducive to increased survival chances of the resulting democracy. There are a number of potential causes or explanations for this pattern, but it is beyond the scope of the current article to carry out analyses of all potential control variables that can be argued to be relevant. For now, we point out the correlation and leave causality for future analyses. Further, results strongly suggest that incremental institutional steps have followed unique, not common, reform paths for each country. This supports the analogy with diffusion of innovation models. The most important details of our findings are the following.

So far, 24 out of 79 transitions to democracy since 1800 have ultimately resulted in failure. We found a clear correlation between the transition time from autocracy to democracy and the survival time as a democracy. We also identified, using our new approach, a consolidation-preparing period of 12 years to establish the foundations for longer-term survival of democracy. Hasty transitions to democracy seem to threaten longer-run survival of democracy. Patience and faith in reaching a sustainable social contract at a national scale is apparently a critical virtue in the formation of a new democracy-as well as probably being an important factor behind its longer-run survival.

Results also confirm, contrary to what is often assumed, that transitions to democracy are normally institutionally rapid and in that sense revolutionary and institutionally dramatic as the previous regime foundations are overthrown before having reached a consensus about what should replace them, with institutional outcomes that may vary widely. There is no standard lane towards democracy except an immediate implementation. This is indeed a result in line with the diffusion of innovation models and their assumptions on variance in susceptibility. This fact unfortunately leaves us with few hints about how to evaluate the potential success of individual cases of revolutions with regard to creating consolidated and stable democracies. Our conclusion is therefore that while most transitions to democracy are rapid, patience increases the likelihood of success-up to a consolidation-preparing period of 12 years. However, each country reforming itself to democracy has found its own unique path, and there are no reasons to think that this will change in the transformation of remaining non-democracies if they succeed in democratization. Adoption of the institutions of democracy in that sense seems analogous to the adoption of new communication standards, but in this case of political nature, the innovation being the involvement of-in principle-all adult citizens on an equal basis. The prerequisite for democracy is finding a contract between all major interests in a nation to accept this principle.

\section{Acknowledgements and the role of the funding source}

The authors thank two anonymous reviewers, M Enquist, $\mathrm{K}$ Eriksson, and $\mathrm{J}$ Lind for discussions and comments. This research was supported by the CULTAPTATION project (European Commission contract FP6-2004-NEST-PATH-043434) and the Swedish Research Council (P Lindenfors and M Sandberg). 
The sponsors have not influenced the design of analysis, the collection, analysis, and interpretation of data, the writing of the report, nor the decision to submit the paper for publication.

\section{Appendix A. Operational definitions of autocracy and democracy: Polity IV variables and weights}

Source: Marshall, Monty G., and Keith Jaggers, 'Political Regime Characteristics and Transitions, 1800-2002: Dataset Users' Manual', in Polity IV Project, 2010 (available at http:// www.systemicpeace.org/inscr/p4manualv2009.pdf, accessed March 9, 2011, University of Maryland, College Park, MD), pp. $14-27$.

\begin{tabular}{llllll}
\hline Democracy & & & Autocracy & & Neither \\
\cline { 1 - 2 } \cline { 5 - 6 } $\begin{array}{l}\text { Authority } \\
\text { coding }\end{array}$ & $\begin{array}{l}\text { Scale } \\
\text { weight }\end{array}$ & $\begin{array}{l}\text { Authority } \\
\text { coding }\end{array}$ & $\begin{array}{l}\text { Scale } \\
\text { weight }\end{array}$ & $\begin{array}{l}\text { Authority } \\
\text { coding }\end{array}$ \\
\hline
\end{tabular}

1 Regulation of chief executive recruitment

(1) Unregulated
(2) Designational/
transitional
(3) Regulated
(0) Not
applicable

2 Competitiveness of executive recruitment
(3) Election
2
(1) Selection 2
(0) Not

(2) Transitional 1

3 Openness of executive recruitment
(3) Dual/
(1) Closed
election
(2) Dual/
(0) Not
(4) Election
(2) Dual/
designation

4 Constraints on chief executive

$\begin{array}{lll}\text { (7) Executive } 4 & \text { (1) Unlimited } 3\end{array}$

parity or

authority

subordination

\begin{tabular}{|c|c|c|}
\hline \multirow{2}{*}{\multicolumn{2}{|c|}{$\begin{array}{l}\text { (6) } \\
\text { Intermediate } \\
\text { category }\end{array}$}} & (2) \\
\hline & & $\begin{array}{l}\text { Intermediate } \\
\text { category }\end{array}$ \\
\hline $\begin{array}{l}\text { (5) Substantial } \\
\text { limitations }\end{array}$ & 2 & $\begin{array}{l}\text { (3) Slight or } \\
\text { moderate } \\
\text { limitations }\end{array}$ \\
\hline $\begin{array}{l}(4) \\
\text { Intermediate } \\
\text { category }\end{array}$ & 1 & \\
\hline
\end{tabular}

(4) Restricted 2

(1) Unregulated

(3) Sectarian $1 \quad$ (2) Multiple

identity

(5) Regulated

6 Competitiveness of political participation
(5) Competitive 3
(1) Repressed 2
(4) Transitional 2
(2) Suppressed 1
(3) Factional 1
(0) Not
applicable

Note: The combined polity score is computed by subtracting the autocracy score from the democracy score, which then ranges from -10 (strongly autocratic) to 10 (strongly democratic). The second variable is always 0 when the first is 1 , and can be 0 when the first variable is 2 , but not otherwise. The third variable is always 0 when the second is 0 , but not otherwise. The sixth variable is always 0 when the fifth is 1 . All other combinations are theoretically possible. Thus we get $(2+2 \cdot 3 \cdot 4) 7(1+4 \cdot 6)=4550$ possible combinations.

\section{Appendix B. Transitions from and to democracy 1800-2008}

\begin{tabular}{|c|c|c|c|c|}
\hline Country & $\begin{array}{l}\text { Start } \\
\text { date of } \\
\text { transition }\end{array}$ & $\begin{array}{l}\text { Date of } \\
\text { new polity }\end{array}$ & Days & Transition \\
\hline France & 11 Apr 1814 & 24 Feb 1848 & 12,371 & Autoc $\rightarrow$ Democ \\
\hline Netherlands & 15 Oct 1848 & 16 Nov 1917 & 25,232 & Autoc $\rightarrow$ Democ \\
\hline Denmark & 5 Jun 1849 & 6 Jun 1915 & 24,105 & Autoc $\rightarrow$ Democ \\
\hline France & 2 Dec 1851 & 3 Nov 1852 & 336 & Democ $\rightarrow$ Autoc \\
\hline Sweden & 30 Jun 1855 & 1 Jul 1917 & 22645 & Autoc $\rightarrow$ Democ \\
\hline Japan & 29 Jul 1858 & 29 Apr 1952 & 34,241 & Autoc $\rightarrow$ Democ \\
\hline Austria & 15 Feb 1861 & 2 Oct 1920 & 21,777 & Autoc $\rightarrow$ Democ \\
\hline Prussia & 8 Jul 1867 & 1 Aug 1919 & 19,015 & Autoc $\rightarrow$ Democ \\
\hline Spain & 18 Sep 1868 & 1 Jul 1900 & 11,607 & Autoc $\rightarrow$ Democ \\
\hline France & 6 Sep 1869 & 14 Dec 1877 & 3020 & Autoc $\rightarrow$ Democ \\
\hline Norway & 18 Jul 1873 & 16 Feb 1898 & 8978 & Autoc $\rightarrow$ Democ \\
\hline Portugal & 1 Feb 1908 & 21 Aug 1911 & 1296 & Autoc $\rightarrow$ Democ \\
\hline Greece & 5 Nov 1915 & 26 Jun 1925 & 3520 & Democ $\rightarrow$ Autoc \\
\hline Spain & 13 Sep 1923 & 14 Sep 1923 & 0 & Democ $\rightarrow$ Autoc \\
\hline Poland & 14 May 1926 & 24 Apr 1935 & 3266 & Democ $\rightarrow$ Autoc \\
\hline Portugal & 28 May 1926 & 31 Jul 1930 & 1524 & Democ $\rightarrow$ Autoc \\
\hline Greece & 24 Sep 1926 & 25 Sep 1926 & 0 & Autoc $\rightarrow$ Democ \\
\hline Spain & 28 Jan 1930 & 10 Dec 1931 & 680 & Autoc $\rightarrow$ Democ \\
\hline Austria & 4 Mar 1933 & 31 Jul 1934 & 513 & Democ $\rightarrow$ Autoc \\
\hline Germany & 14 Jul 1933 & 15 Jul 1933 & 0 & Democ $\rightarrow$ Autoc \\
\hline Estonia & 16 Oct 1933 & 26 Feb 1936 & 862 & Democ $\rightarrow$ Autoc \\
\hline Latvia & 17 May 1934 & 18 May 1934 & 0 & Democ $\rightarrow$ Autoc \\
\hline Greece & 4 Aug 1936 & 5 Aug 1936 & 0 & Democ $\rightarrow$ Autoc \\
\hline Venezuela & 4 Feb 1937 & 8 Dec 1958 & 7976 & Autoc $\rightarrow$ Democ \\
\hline Austria & 15 Mar 1938 & 29 Jun 1946 & 3027 & Autoc $\rightarrow$ Democ \\
\hline Spain & 1 Apr 1939 & 2 Apr 1939 & 0 & Democ $\rightarrow$ Autoc \\
\hline France & 14 Jun 1940 & 15 Jun 1940 & 0 & Democ $\rightarrow$ Autoc \\
\hline Greece & 24 Apr 1941 & 31 Dec 1944 & 1346 & Autoc $\rightarrow$ Democ \\
\hline Italy & 15 Sep 1943 & 1 Jan 1948 & 1568 & Autoc $\rightarrow$ Democ \\
\hline France & 24 Aug 1944 & 14 Oct 1946 & 780 & Autoc $\rightarrow$ Democ \\
\hline Brazil & 25 Oct 1945 & 19 Sep 1946 & 328 & Autoc $\rightarrow$ Democ \\
\hline Turkey & 8 Jan 1946 & 9 Jan 1946 & 0 & Autoc $\rightarrow$ Democ \\
\hline Czechoslovakia & 15 Sep 1947 & 5 May 1948 & 232 & Democ $\rightarrow$ Autoc \\
\hline Greece & 16 Oct 1949 & 22 Apr 1967 & 6396 & Democ $\rightarrow$ Autoc \\
\hline Syria & 25 Feb 1954 & 26 Feb 1954 & 0 & Autoc $\rightarrow$ Democ \\
\hline Syria & 1 Feb 1958 & 9 Mar 1963 & 1861 & Democ $\rightarrow$ Autoc \\
\hline Pakistan & 7 Oct 1958 & 8 Oct 1958 & 0 & Democ $\rightarrow$ Autoc \\
\hline Sudan & 17 Nov 1958 & 18 Nov 1958 & 0 & Democ $\rightarrow$ Autoc \\
\hline Laos & 1 Jan 1960 & 3 Dec 1975 & 5814 & Democ $\rightarrow$ Autoc \\
\hline Korea South & 16 May 1961 & 17 May 1961 & 0 & Democ $\rightarrow$ Autoc \\
\hline $\begin{array}{l}\text { Dominican } \\
\text { Republic }\end{array}$ & 30 May 1961 & 20 Dec 1962 & 568 & Autoc $\rightarrow$ Democ \\
\hline Brazil & 2 Sep 1961 & 28 Oct 1965 & 1516 & Democ $\rightarrow$ Autoc \\
\hline $\begin{array}{l}\text { Myanmar } \\
\text { (Burma) }\end{array}$ & 2 Mar 1962 & 3 Mar 1962 & 0 & Democ $\rightarrow$ Autoc \\
\hline Sudan & 22 Oct 1964 & 22 Apr 1965 & 181 & Autoc $\rightarrow$ Democ \\
\hline Nigeria & 15 Jan 1966 & 16 Jan 1966 & 0 & Democ $\rightarrow$ Autoc \\
\hline Uganda & 15 Apr 1966 & 10 Sep 1967 & 512 & Democ $\rightarrow$ Autoc \\
\hline Sierra Leone & 23 Mar 1967 & 24 Mar 1967 & 0 & Democ $\rightarrow$ Autoc \\
\hline Sudan & 25 May 1969 & 13 Oct 1971 & 870 & Democ $\rightarrow$ Autoc \\
\hline Somalia & 21 Oct 1969 & 22 Oct 1969 & 0 & Democ $\rightarrow$ Autoc \\
\hline Lesotho & 30 Jan 1970 & 31 Jan 1970 & 0 & Democ $\rightarrow$ Autoc \\
\hline Uruguay & 28 Nov 1971 & 9 Feb 1973 & 438 & Democ $\rightarrow$ Autoc \\
\hline Argentina & 11 Mar 1973 & 12 Mar 1973 & 0 & Autoc $\rightarrow$ Democ \\
\hline Chile & 11 Sep 1973 & 12 Sep 1973 & 0 & Democ $\rightarrow$ Autoc \\
\hline Brazil & 15 Jan 1974 & 16 Jan 1985 & 4018 & Autoc $\rightarrow$ Democ \\
\hline Portugal & 24 Apr 1974 & 26 Apr 1976 & 732 & Autoc $\rightarrow$ Democ \\
\hline Greece & 23 Jul 1974 & 8 Jun 1975 & 319 & Autoc $\rightarrow$ Democ \\
\hline Bangladesh & 16 Dec 1974 & 8 Nov 1975 & 326 & Democ $\rightarrow$ Autoc \\
\hline Spain & 22 Nov 1975 & 30 Dec 1978 & 1133 & Autoc $\rightarrow$ Democ \\
\hline Argentina & 24 Mar 1976 & 25 Mar 1976 & 0 & Democ $\rightarrow$ Autoc \\
\hline Pakistan & 5 Jul 1977 & 6 Jul 1977 & 0 & Democ $\rightarrow$ Autoc \\
\hline Mexico & 1 Sep 1977 & 6 Jul 1997 & 7247 & Autoc $\rightarrow$ Democ \\
\hline Thailand & 20 Nov 1977 & 14 Sep 1992 & 5411 & Autoc $\rightarrow$ Democ \\
\hline Peru & 4 Jun 1978 & 29 Jul 1980 & 785 & Autoc $\rightarrow$ Democ \\
\hline
\end{tabular}

(continued on next page) 
Appendix B (continued)

\begin{tabular}{|c|c|c|c|c|}
\hline Country & $\begin{array}{l}\text { Start } \\
\text { date of } \\
\text { transition }\end{array}$ & $\begin{array}{l}\text { Date of } \\
\text { new polity }\end{array}$ & Days & Transition \\
\hline Ghana & $5 \mathrm{Jul} 1978$ & $2 \operatorname{Jan} 1979$ & 180 & Autoc $\rightarrow$ Democ \\
\hline Senegal & 19 Sep 1978 & 20 Mar 2000 & 7852 & Autoc $\rightarrow$ Democ \\
\hline Nigeria & 21 Sep 1978 & 2 Oct 1979 & 375 & Autoc $\rightarrow$ Democ \\
\hline Nicaragua & 19 Jul 1979 & 27 Feb 1990 & 3875 & Autoc $\rightarrow$ Democ \\
\hline El Salvador & 15 Oct 1979 & 2 Jun 1984 & 1691 & Autoc $\rightarrow$ Democ \\
\hline Korea South & 3 Mar 1981 & 26 Feb 1988 & 2550 & Autoc $\rightarrow$ Democ \\
\hline Nepal & 9 May 1981 & 17 May 1999 & 6581 & Autoc $\rightarrow$ Democ \\
\hline Ghana & 31 Dec 1981 & 1 Jan 1982 & 0 & Democ $\rightarrow$ Autoc \\
\hline Bolivia & 10 Oct 1982 & 11 Oct 1982 & 0 & Autoc $\rightarrow$ Democ \\
\hline Argentina & 30 Oct 1983 & 31 Oct 1983 & 0 & Autoc $\rightarrow$ Democ \\
\hline Nigeria & 1 Jan 1984 & 2 Jan 1984 & 0 & Democ $\rightarrow$ Autoc \\
\hline Uruguay & 1 Mar 1985 & 2 Mar 1985 & 0 & Autoc $\rightarrow$ Democ \\
\hline Pakistan & 10 Mar 1985 & 17 Nov 1988 & 1347 & Autoc $\rightarrow$ Democ \\
\hline Sudan & 6 Apr 1985 & 2 Apr 1986 & 360 & Autoc $\rightarrow$ Democ \\
\hline Guatemala & 31 May 1985 & 16 Jan 1996 & 3881 & Autoc $\rightarrow$ Democ \\
\hline Philippines & $25 \mathrm{Feb} 1986$ & 3 Feb 1987 & 342 & Autoc $\rightarrow$ Democ \\
\hline Bangladesh & 10 Nov 1986 & 26 Sep 1991 & 1780 & Autoc $\rightarrow$ Democ \\
\hline Taiwan & 14 Jul 1987 & 20 Dec 1992 & 1985 & Autoc $\rightarrow$ Democ \\
\hline Hungary & 22 May 1988 & $3 \mathrm{Feb}$ & 621 & Autoc $\rightarrow$ Democ \\
\hline Chile & 5 Oct 1988 & 16 Dec 1989 & 436 & Autoc $\rightarrow$ Democ \\
\hline Poland & $6 \mathrm{Feb}$ & $2 \mathrm{Jul}$ & 875 & Autoc $\rightarrow$ Democ \\
\hline Paragua & 1 May 1989 & 23 Jun 1992 & 1148 & Autoc $\rightarrow$ Democ \\
\hline Sudan & 30 Jun 1989 & 1 Jul 1989 & 0 & Democ $\rightarrow$ Autoc \\
\hline Panama & 20 Dec 1989 & 21 Dec 1989 & 0 & Autoc $\rightarrow$ Democ \\
\hline Romania & 26 Dec 1989 & 16 Nov 1996 & 2516 & Autoc $\rightarrow$ Democ \\
\hline Benin & 25 Feb 1 & 25 Mar 1991 & 392 & Autoc $\rightarrow$ Democ \\
\hline Comoro & 0 & $21 \mathrm{~A} r \ln$ & 5145 & Autoc $\rightarrow$ Democ \\
\hline Bulgaria & 29 Mar 1990 & 30 Mar 1990 & 0 & Autoc $\rightarrow$ Democ \\
\hline Czechoslovakia & 8 Jun 1990 & 9 Jun 1990 & 0 & Autoc $\rightarrow$ Democ \\
\hline Mongolia & 29 Jul 1990 & 14 Jan 1992 & 533 & Autoc $\rightarrow$ Democ \\
\hline Liberia & 16 Sep 1990 & 16 Jan 2006 & 5600 & Autoc $\rightarrow$ Democ \\
\hline Albania & 11 Dec 1990 & 25 Jul 2002 & 4243 & Autoc $\rightarrow$ Democ \\
\hline Haiti & 15 Dec 1 & c 1990 & 0 & Autoc $\rightarrow$ Democ \\
\hline Mali & $26 \mathrm{Mar}$ & 9 Jun & 440 & Autoc $\rightarrow$ Democ \\
\hline Ghana & 10 May 1991 & 7 Jan 2001 & 3529 & Autoc $\rightarrow$ Democ \\
\hline Niger & 29 Jul 1991 & 27 Dec 1992 & 516 & Autoc $\rightarrow$ Democ \\
\hline Haiti & 30 Sep 1991 & 1 Oct 1991 & 0 & Democ $\rightarrow$ Autoc \\
\hline Zambia & 31 Oct 1991 & 1 Nov 1991 & 0 & Autoc $\rightarrow$ Democ \\
\hline Madagascar & 31 Oct 1991 & 26 Nov 1992 & 391 & Autoc $\rightarrow$ Democ \\
\hline Kenya & 3 Dec 1991 & 30 Dec 2002 & 4044 & Autoc $\rightarrow$ Democ \\
\hline Burundi & 16 Mar 1992 & 19 Aug 2005 & 4903 & Autoc $\rightarrow$ Democ \\
\hline Guyana & 5 Oct & 6 Oct & 0 & Autoc $\rightarrow$ Democ \\
\hline Lesotho & 27 Mar 1993 & 28 Mar 1993 & 0 & Autoc $\rightarrow$ Democ \\
\hline Malawi & 17 May 1994 & 18 May 1994 & 0 & Autoc $\rightarrow$ Democ \\
\hline Guinea-Bissau & 3 Jul 1994 & 1 Oct 2005 & 4107 & Autoc $\rightarrow$ Democ \\
\hline Gambia & 23 Jul 1994 & 24 Jul 1994 & 0 & Democ $\rightarrow$ Autoc \\
\hline Haiti & 15 Oct 1994 & 16 Oct 1994 & 0 & Autoc $\rightarrow$ Democ \\
\hline Mozambique & 27 Oct 1994 & 28 Oct 1994 & 0 & Autoc $\rightarrow$ Democ \\
\hline Belarus & 15 Apr 1995 & 25 Nov 1996 & 58 & Democ $\rightarrow$ Autoc \\
\hline Armenia & $6 \mathrm{Jul} 19 \mathrm{~s}$ & 28 Sep 1996 & 449 & Democ $\rightarrow$ Autoc \\
\hline Niger & 28 Jan 1996 & 29 Jan 1996 & 0 & Democ $\rightarrow$ Autoc \\
\hline Sierra Leone & 16 Mar 1996 & 17 Sep 2007 & 4201 & Autoc $\rightarrow$ Democ \\
\hline Indonesia & 21 May 1998 & 21 Oct 1999 & 517 & Autoc $\rightarrow$ Democ \\
\hline Niger & 9 Apr 1999 & 16 Nov 2004 & 2047 & Autoc $\rightarrow$ Democ \\
\hline Pakistan & 12 Oct 1999 & 13 Oct 1999 & 0 & Democ $\rightarrow$ Autoc \\
\hline Yugoslavia & 26 Oct 2000 & 27 Oct 2000 & 0 & Autoc $\rightarrow$ Democ \\
\hline Nepal & 4 Oct 2002 & 5 Oct 2002 & 0 & Democ $\rightarrow$ Autoc \\
\hline Nepal & 24 Apr 2006 & 18 May 2006 & 23 & Autoc $\rightarrow$ Democ \\
\hline Bangladesh & 10 Jan 2007 & 11 Jan 2007 & 0 & Democ $\rightarrow$ Autoc \\
\hline
\end{tabular}

\section{References}

[1] J.J. Linz, A.C. Stepan, Problems of Democratic Transition and Consolidation: Southern Europe, South America, and Post-communist Europe, 1996.

[2] S. Bowles, H. Gintis, A Cooperative Species: Human Reciprocity and Its Evolution, Princeton University Press, Princeton, 2011.

[3] O.E. Williamson, The Economic Institutions of Capitalism: Firms, Markets, Relational Contracting, Free Press, New York, 1985.
[4] M. Aoki, Toward a Comparative Institutional Analysis, MIT Press, Cambridge, Mass., 2001

[5] S. Bowles, Microeconomics: Behavior, Institutions, and Evolution, Princeton University Press, Princeton, N.J.; Woodstock, 2004.

[6] M.A. Nowak, R. Highfield, SuperCooperators: altruism, evolution, and why we need each other to succeed, 1st Free Press hardcover ed., Free Press, New York, 2011.

[7] E. Ostrom, Governing the Commons: The Evolution of Institutions for Collective Action, Cambridge University Press, Cambridge [England]; New York, 1990.

[8] H.P. Young, Individual Strategy and Social Structure: An Evolutionary Theory of Institutions, Princeton University Press, Princeton, N.J., 1998

[9] G.M. Hodgson, Evolution and Institutions: On Evolutionary Economics and the Evolution of Economics, in: Geoffrey M. Hodgson (Ed.), Edward Elgar, Cheltenham, 2000.

[10] M. Sandberg, P. Lundberg, Political institutions and their historical dynamics, PLoS One 7 (10) (2012) e45838, http://dx.doi.org/10.1371/journal.pone. 0045838.

[11] A. Przeworski, Democracy as an equilibrium, Public Choice 123 (2005) 253-273.

[12] K.G. Binmore, Natural Justice, Oxford University Press, New York, 2005.

[13] G. Modelski, Long Cycles in World Politics, University of Washington Press, Seattle, 1987.

[14] P. Lindenfors, F. Jansson, M. Sandberg, The cultural evolution of democracy: saltational changes in a political regime landscape, PLoS One 6 (2011) e28270.

[15] D.C. Dennett, Darwin's Dangerous Idea: Evolution and the Meanings of Life, Simon \& Schuster, New York, 1995.

[16] F.M. Bass, A new product growth for model consumer durables, Manag. Sci. 15 (1969) 215, (pre-1986).

[17] N. Meade, T. Islam, Modelling and forecasting the diffusion of innovation - a 25-year review, Int. J. Forecast. 22 (2006) 519.

[18] M. Sandberg, Soft Power, World System Dynamics, and Democratization: A Bass Model of Democracy Diffusion 1800-2000, J. Artif. Soc. Soc. Simul. 14 (2011) 4

[19] G. Modelski, G. Perry, "Democratization in long perspective" revisited, Technol. Forecast. Soc. Chang. 69 (2002) 359-376.

[20] E.M. Rogers, Diffusion of Innovations, 5th ed. Free Press, New York, 2003.

[21] C. Marchetti, Modeling innovation diffusion, in: B. Henry (Ed.), Forecasting Technological Innovation, Kluwer, Dordrecht, 1991, pp. 55-77.

[22] in: Encyclopædia Britannica London, 2011.

[23] J.A. Schumpeter, The creative response in economic history, J. Econ. Hist. VII (1947) 149-159.

[24] J.A. Schumpeter, The Theory of Economic Development; An Inquiry into Profits, Capital, Credit, Interest, and the Business Cycle, Harvard University Press, Cambridge, Mass., 1934

[25] J.A. Schumpeter, Capitalism, Socialism, and Democracy, Harper \& Brothers, New York, London, 1942.

[26] R.A. Dahl, Polyarchy; Participation and Opposition, Yale University Press, New Haven, 1971.

[27] T. Vanhanen, Prospects of Democracy: A Study of 172 Countries, Routledge, New York, 1997.

[28] S. Gates, H. Hegre, M.P. Jones, H. Strand, Institutional inconsistency and political instability: polity duration, 1800-2000, Am. J. Polit. Sci. 50 (2006) 893-908.

[29] K.S. Gleditsch, M.D. Ward, Diffusion and the international context of democratization, Int. Organ. 60 (2006) 911-933.

[30] T.R. Gurr, Persistence and change in political systems, 1800-1971, Am. Polit. Sci. Rev. 68 (1974) 1482-1504.

[31] K. Jaggers, T.R. Gurr, Tracking democracy's third wave with the Polity III data, J. Peace Res. 32 (1995) 469-482.

[32] M.G. Marshall, Keith Jaggers, Political regime characteristics and transitions, 1800-2002: dataset users' manual, Polity IV Project, University of Maryland, College Park, MD, 2002.

[33] K.S. Gleditsch, M.D. Ward, Double take, J. Confl. Resolut. 41 (1997) 361-383.

[34] S. Treier, S. Jackman, Democracy as a latent variable, Am. J. Polit. Sci. 52 (2008) 201-217.

[35] J.J. Linz, A.C. Stepan, Problems of Democratic Transition and Consolidation: Southern Europe, South America, and Post-communist Europe, Johns Hopkins Univ. Press, Baltimore, 1996.

[36] S.P. Huntington, The Third Wave: Democratization in the Late Twentieth Century, University of Oklahoma Press, Norman, 1991.

[37] S. Mainwaring, G.A. O'Donnell, J.S. Valenzuela, Issues in Democratic Consolidation: The New South American Democracies in Comparative Perspective, Published for the Helen Kellogg Institute for International Studies by University of Notre Dame Press, Notre Dame, Ind., 1992

[38] G. Di Palma, To Craft Democracies: An Essay on Democratic Transitions, University of California Press, Berkeley, 1990. 
[39] A. Przeworski, Democracy and the Market: Political and Economic Reforms in Eastern Europe and Latin America, Cambridge University Press, Cambridge, 1991.

[40] S. Haggard, R. Kaufman, The Political Economy of Democratic Transitions, Comp. Polit. 29 (3) (1997) 263-283.

[41] S.P. Huntington, The third wave: democratization in the late twentieth century, The Julian J. Rothbaum Distinguished Lecture Series, 1991.

[42] J. Teorell, Determinants of Democratization: Explaining Regime Change in the World, 1972-2006, Cambridge University Press, Cambridge; New York, 2010.

[43] H. Starr, Democratic dominoes: diffusion approaches to the spread of democracy in the international system, J. Confl. Resolut. 35 (1991) 356-381.

[44] J. O'Loughlin, M.D. Ward, C.L. Lofdahl, J.S. Cohen, D.S. Brown, D. Reilly, K.S. Gleditsch, M. Shin, The diffusion of democracy, 1946-1994, Ann. Assoc. Am. Geogr. 88 (1998) 545-574.

[45] D. Brinks, M. Coppedge, Patterns of diffusion in the third wave of democracy, Annual Meeting of American Political Science Association, San Fransisco, CA, 2001.

[46] K. Gleditsch, M. Ward, Diffusion and the International Context of Democratization, Int. Organ. 60 (4) (2006) 911-933.

[47] H. Starr, C. Lindborg, Democratic dominoes revisited: the hazards of governmental transitions, 1974-1996, J. Confl. Resolut. 47 (2003) 490-519.

[48] D. Brinks, M. Coppedge, Diffusion is no illusion - neighbor emulation in the third wave of democracy, Comp. Polit. Stud. 39 (2006) 463-489.

[49] B. Wejnert, Diffusion, development, and democracy, 1800-1999, Am. Sociol. Rev. 70 (2005) 53-81.

[50] P. Pierson, Politics in Time: History, Institutions, and Social Analysis, Princeton University Press, Princeton, 2004.

[51] B. Moore, Social Origins of Dictatorship and Democracy; Lord and Peasant in the Making of the Modern World, Beacon Press, Boston, 1966.

[52] M. Burton, R. Gunther, J. Higley, Introduction: elite transformation and democratic regimes, in: J. Higley, R. Gunther (Eds.), Elites and Democratic Consolidation in Latin America and Southern Europe, Cambridge University Press, Cambridge, 1992, pp. 1-37.

[53] J. Mahoney, Knowledge accumulation in comparative historical research: the case of democracy and authoritarianism, in: J. Mahoney, D. Rueschmeyer (Eds.), Comparative Historical Analysis in the Social Sciences, Cambridge University Press, Cambridge, 2003.

[54] M.J. Gasiorowski, T.J. Power, The structural determinants of democratic consolidation. evidence from the Third World, Comp. Polit. Stud. 31 (1998) 740-771.

[55] M. Bernhard, C. Reenok, T. Nordstrom, Economic performance and survival in new democracies. is there a honeymoon effect? Comp. Polit. Stud. 36 (2003) 404-431.

[56] M. Svolik, Authoritarian reversals and democratic consolidation, Am. Polit. Sci. Rev. 102 (2008) 153-168.
[57] D.A. Rustow, Transitions to democracy, Comp. Polit. 2 (1970) 337-363.

[58] G.A. O'Donnell, P.C. Schmitter, Transitions from Authoritarian Rule: Tentative Conclusions about Uncertain Democracies, Johns Hopkins University Press, Baltimore, 1986.

[59] F.M. Bass, "Comments on 'A New Product Growth for Model Consumer Durables'", Manag. Sci. 50 (12 Supplement) (2004) 1833-1840, (footnote 16).

[60] M.G. Marshall, K. Jaggers, Polity IV Project: Political Regime Characteristics and Transitions 1800-2008, University of Maryland, 2010.

[61] S.M. Lipset, The social requisites of democracy revisited: 1993 presidential address, Am. Sociol. Rev. 59 (1994) 1-22.

[62] R. Inglehart, C. Welzel, Modernization, Cultural Change, and Democracy: The Human Development Sequence, 2005. (x, 333 pp.).

[63] H. Eckstein, T.R. Gurr, Patterns of Authority: A Structural Basis for Political Inquiry, Wiley-Interscience, London, 1975.

Fredrik Jansson is a postgraduate researcher, with a background in mathematics, computer science and language, at the Centre for the Study of Cultural Evolution, where he works on mathematical models of human behavior, what shapes human culture (like norms and democratic institutions) and how it spreads. The models are often integrated with empirical research, by using existing real-world data and performing experimental behavioral studies. He is currently finishing his $\mathrm{PhD}$ studies.

Patrik Lindenfors has a $\mathrm{PhD}$ in Zoological Ecology from Stockholm University. He is currently an Associate Professor at both the Department of Zoology and the Centre for the Study of Cultural Evolution there. He is an associate editor of the Journal Evolution. He works within two different scientific domains. At the Centre of Cultural Evolution he mainly carries out empirical investigations of how culture evolves. At the Department of Zoology his main focus is on the evolution of sexual differences and the development of methods to analyze biological evolution.

Mikael Sandberg is a professor in political science at Halmstad University, Sweden. He is also an affiliate of the Centre for the Study of Cultural Evolution at the University of Stockholm. He was Visiting Scholar at University College London in 2010, Karl Deutsch Guest Professor at Wissenschaftszentrum Berlin für Sozialforschung (WZB) in 1997, and research scholar at the UNU University Institute for New Technologies, Maastricht in 1995-96. He has particularly focused on evolutionary systems theory, memetics applied to political science, and dynamic models of social change, such as diffusion theory applied to studies of political and technological change. 